\title{
Unicuspid aortic valve with aortic stenosis - importance of a comprehensive clinical and echocardiographic approach for optimal intervention timing
}

\author{
(DDubravka Šipuš* , \\ DBlanka Glavaš Konja, \\ DSandra Jakšić \\ Jurinjak, \\ (D)Marija Brestovac, \\ DDadranka Šeparović \\ Hanževački, \\ (i) Vlatka Rešković \\ Lukšić
}

University of Zagreb School of Medicine, University Hospital Centre Zagreb, Zagreb, Croatia

RECEIVED:

March 28, 2021

ACCEPTED:

April 2, 2021

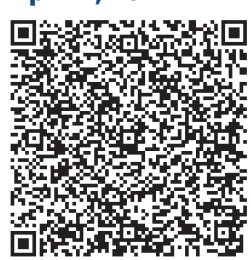

KEYWORDS: unicuspid aortic valve, aortic stenosis, echocardiography, stress echocardiography. CITATION: Cardiol Croat. 2021;16(5-6):183-4. | https://doi.org/10.15836/ccar2021.183

*ADDRESS FOR CORRESPONDENCE: Dubravka Šipuš, Klinički bolnički centar Zagreb, Kišpatićeva 12, HR-10000 Zagreb, Croatia. / Phone: +385-91-7344-878 / E-mail: dubravka.sipus@gmail.com

ORCID: Dubravka Šipuš, https://orcid.org/0000-0002-5631-0353 • Blanka Glavaš Konja, https://orcid.org/0000-0003-1134-4856 Sandra Jakšić Jurinjak, https://orcid.org/0000-0002-7349-6137 • Marija Brestovac, https://orcid.org/0000-0003-1542-2890 Jadranka Šeparović Hanževački, https://orcid.org/0000-0002-3437-6407

Vlatka Rešković Lukšić, https://orcid.org/0000-0002-4721-3236

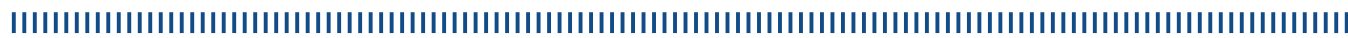

Background: Unicuspid aortic valve (UAV) is a rare congenital malformation observed in $0.02 \%$ of population ${ }^{1}$. It shares several characteristics with bicuspid aortic valve (BAV), such as premature valvular calcification and aortic root dilatation which occur more rapidly in UAV. UAV most often presents with aortic stenosis (AS), either isolated or concomitant with aortic regurgitation ${ }^{2}$.

Case report: 47-year-old female was diagnosed with BAV and AS at the age of four. She underwent regular echocardiographic follow-ups and was asymptomatic, which was regularly confirmed with stress tests. She had two uncomplicated pregnancies and one miscarriage. In 2019, stress echocardiography showed good functional capacity and preserved left ventricular (LV) function, with good improvement in LV ejection fraction (LVEF) and global longitudinal strain (GLS) during exercise, normal NT-proBNP, but increase in mean pressure gradient (PG) during work-up for $>20 \mathrm{mmHg}$ (Figure 1). Closely follow-up was indicated. In January 2021 she had anaphylactic reaction after food intake. After that event she started to complain of frequent light-headedness and palpitations on effort, without syncope. She underwent thorough neurological and ear, nose and throat evaluation including brain magnetic resonance imaging, and no pathology was found. Laboratory findings showed elevated NTproBNP of $400 \mathrm{ng} / \mathrm{L}$. She was admitted to resolve if the symptoms were truly due to AS. Transthoracic and transesophageal echocardiography (Figure 2) demonstrated a LVEF of 60\%, GLS -22\% and UAV with severe AS (max PG $80 \mathrm{mmHg}$, mean PG $51 \mathrm{mmHg}$, AVA VTI $0.58 \mathrm{~cm}^{2}$ ). MSCT aortography showed slightly dilated ascending aorta, diameter $4,2 \mathrm{~cm}$. On 24-hour ECG recording, nonsustained ventricular tachycardias originating from LV were recorded and correlated with symptoms. Due to arrythmias caused by pressure overloaded LV, elevation in NT-proBNP and clinical correlation, aortic valve replacement was indicated.

Discussion: UAV with AS is rare congenital malformation usually diagnosed in childhood but may advance into adulthood before becoming symptomatic. Echocardiography is a key tool in confirming presence and assessment of severity of AS. Additional value of stress echocardiography is in revealing symptoms or proving truly asymptomatic AS, which is of most importance for timing of surgery. We
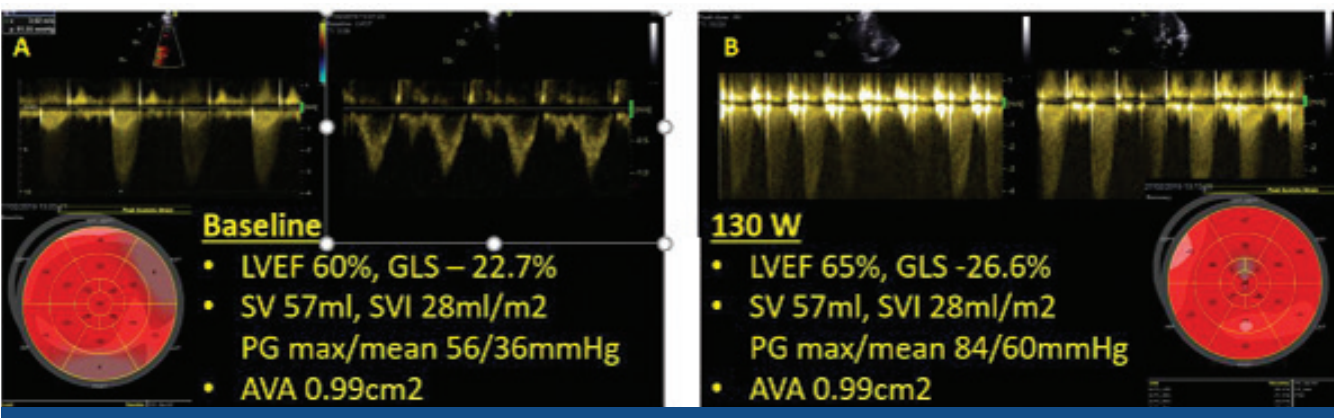

FIGURE 1. Stress echocardiography at baseline (A) and at $130 \mathrm{~W}(\mathrm{~B})$ showing normal response in improvement in left ventricular ejection fraction (LVEF) and global longitudinal strain (GLS). The aortic valve area (AVA) remained unchanged, with increase in the mean pressure gradient (PG) of $24 \mathrm{mmHg}$. The patient was asymptomatic during the test. 
Unicuspid aortic valve with aortic stenosis - importance of a comprehensive clinical and echocardiographic approach for optimal intervention timing

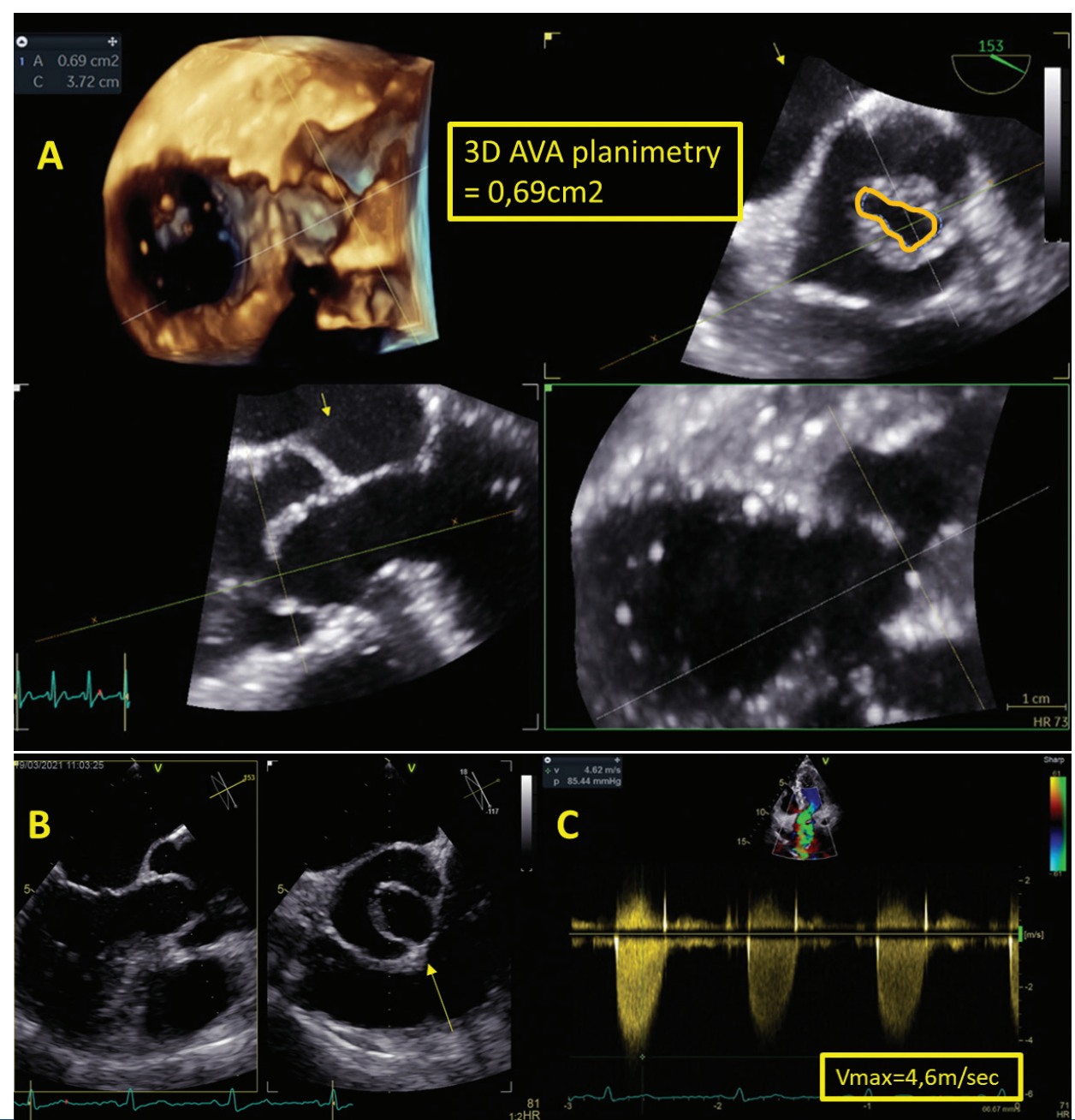

FIGURE 2. 3D transesophageal echocardiography reconstruction for measurement of the 3D aortic valve area (AVA) by planimetry (A). Unicuspid aortic valve shown in TOE X-plane, arrow pointing at single commissural zone of attachment and eccentric valvular orifice during systole (B). Transthoracic measurement of peak velocity across the aortic valve (C).

presented a case of UAV with long asymptomatic phase of the disease. Asymptomatic patients should be re-evaluated every six months for the occurrence of symptoms and change in echocardiographic parameters ${ }^{3}$.

Conclusion: In every case of severe AS, no matter of valve morphology, close clinical and echo follow up, including stress test is crucial in deciding on right timing for intervention.

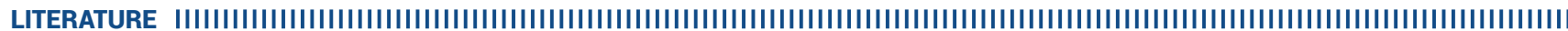

1. Novaro GM, Mishra M, Griffin BP. Incidence and echocardiographic features of congenital unicuspid aortic valve in an adult population. J Heart Valve Dis. 2003 Nov;12(6):674-8. PubMed: https://pubmed.ncbi.nlm.nih.gov/14658804/

2. Mookadam F, Thota VR, Garcia-Lopez AM, Emani UR, Alharthi MS, Zamorano J, et al. Unicuspid aortic valve in adults: a systematic review. J Heart Valve Dis. 2010 Jan;19(1):79-85, PubMed: https://pubmed.ncbi.nlm.nih.gov/20329493/

3. Baumgartner H, Falk V, Bax JJ, De Bonis M, Hamm C, Holm PJ, et al; ESC Scientific Document Group. 2017 ESC/EACTS Guidelines for the management of valvular heart disease. Eur Heart J. 2017 Sep 21;38(36):2739-2791. https://doi.org/10.1093/eurheartj/ehx391 